\section{Cureus}

\title{
Xanthogranulomatous Pyelonephritis Causing Renocolic Fistula Presenting as Symptomatic Anemia
}

\author{
Laith Numan $^{1}$, Harris Zamir ${ }^{1}$, Nedaa M. Husainat ${ }^{2}$, Mohammad Tahboub ${ }^{3}$ \\ 1. Internal Medicine, University of Missouri-Kansas City School of Medicine, Kansas City, USA 2. Kidney \\ Institute, University of Kansas Hospital \& Medical Center, Kansas City, USA 3. Internal Medicine, \\ University of Missouri-Kansas City l Saint Luke's Health System, Kansas City, USA
}

$\square$ Corresponding author: Laith Numan, numanl@umkc.edu

Disclosures can be found in Additional Information at the end of the article

\section{Abstract}

Renocolic fistula is a rare clinical finding that is most commonly iatrogenic after surgical intervention. Herein, we present a case of renocolic fistula secondary to xanthogranulomatous pyelonephritis (XGP) with a subtle presentation as anemia. A 40-year-old female was found to have a hemoglobin of $6.5 \mathrm{~g} / \mathrm{dL}$ after presenting for worsening fatigue. A urinalysis was remarkable for numerous white blood cell (WBC), positive bacteria, and nitrite. As part of her anemia workup, an esophagogastroduodenoscopy (EGD) was done which was normal while a colonoscopy showed a fistula opening with surrounding nodularity close to the splenic flexure of the colon. A computed tomography (CT) scan of the abdomen and pelvis with contrast showed chronic left kidney pyelonephritis with multiple contiguous abscesses in the inferior left kidney in addition to a staghorn calculus concerning for XGP. The patient was started on antibiotics and underwent laparotomy with repair of the renocolic fistula, partial omentectomy, and left nephrectomy. She tolerated the surgery well and was discharged with a stable hemoglobin. XGP is a rare type of chronic pyelonephritis that is usually a result of chronic obstruction by an infected stone. Spontaneous renocolic fistulas are rare nowadays with the advancement in antibiotics and renal stones treatment.

Categories: Internal Medicine, Urology, Gastroenterology

Keywords: renocolic fistula, xanthogranulomatous pyelonephritis (xgp), anemia, kidney stones, colonoscopy findings

\section{Introduction}

Received 06/03/2019

Review began 06/05/2019 Review ended 06/05/2019 Published 06/19/2019

\section{(c) Copyright 2019}

Numan et al. This is an open access article distributed under the terms of the Creative Commons Attribution License CC-BY 3.0., which permits unrestricted use, distribution, and reproduction in any medium, provided the original author and source are credited.
Xanthogranulomatous pyelonephritis (XGP) is an uncommon cause of chronic pyelonephritis arising from obstruction of the kidney by infected renal stones [1]. Granulomatous tissue invades the kidney, and resultant lipid-laden macrophages destroy the renal tissue [2]. These patients commonly present with flank pain, and a unilateral renal mass felt on the physical exam [3]. A rare sequela of this uncommon disease is the renocolic fistula [2]. A renocolic fistula is usually associated with primary bowel pathologies, including inflammatory bowel diseases and malignancies [4]. That is why, without any suspicion for a primary bowel pathology, a diagnosis of renocolic fistula is rarely pursued.

We report a case of renocolic fistula caused by XGP in a patient that presented without a flank pain. Instead, our patient presented with symptomatic anemia and dysuria. XGP was on the differential after a colonoscopy was performed and revealed a renocolic fistula. 


\section{Cureus}

\section{Case Presentation}

A 40-year-old female with no significant past medical history who was seen by her primary care physician for fatigue and workup revealed low hemoglobin, so she was asked to go to the emergency department (ED) for further evaluation. The patient has been complaining of fatigue, nausea, diarrhea, dysuria, and urinary frequency for more than seven days prior to presentation. On physical examination, the patient was pale, had mild abdominal tenderness, and left flank fullness was felt. Labs were repeated in the ED and were remarkable for a hemoglobin of $6.5 \mathrm{~g} / \mathrm{dL}$ (down from $10 \mathrm{~g} / \mathrm{dL}$ three months prior), white blood cell (WBC) count of $18 \times 10^{9} / \mathrm{L}$, creatinine of $1.87 \mathrm{mg} / \mathrm{dL}$ (baseline is $1 \mathrm{mg} / \mathrm{dL}$ ) with blood urea nitrogen (BUN) of $24 \mathrm{mg} / \mathrm{dL}$. Urinalysis was remarkable for numerous WBC, positive bacteria, and nitrite. The patient received one unit of packed red blood cells and was started on ceftriaxone for urinary tract infection (UTI). No source of active bleeding was identified.

Gastroenterology team was consulted for the anemia, and they performed esophagogastroduodenoscopy (EGD) which was normal. Subsequently, they performed a colonoscopy which detected a fistula opening with surrounding nodularity close to the splenic flexure of the colon with a small amount of pus noted coming out of it (Figure 1).

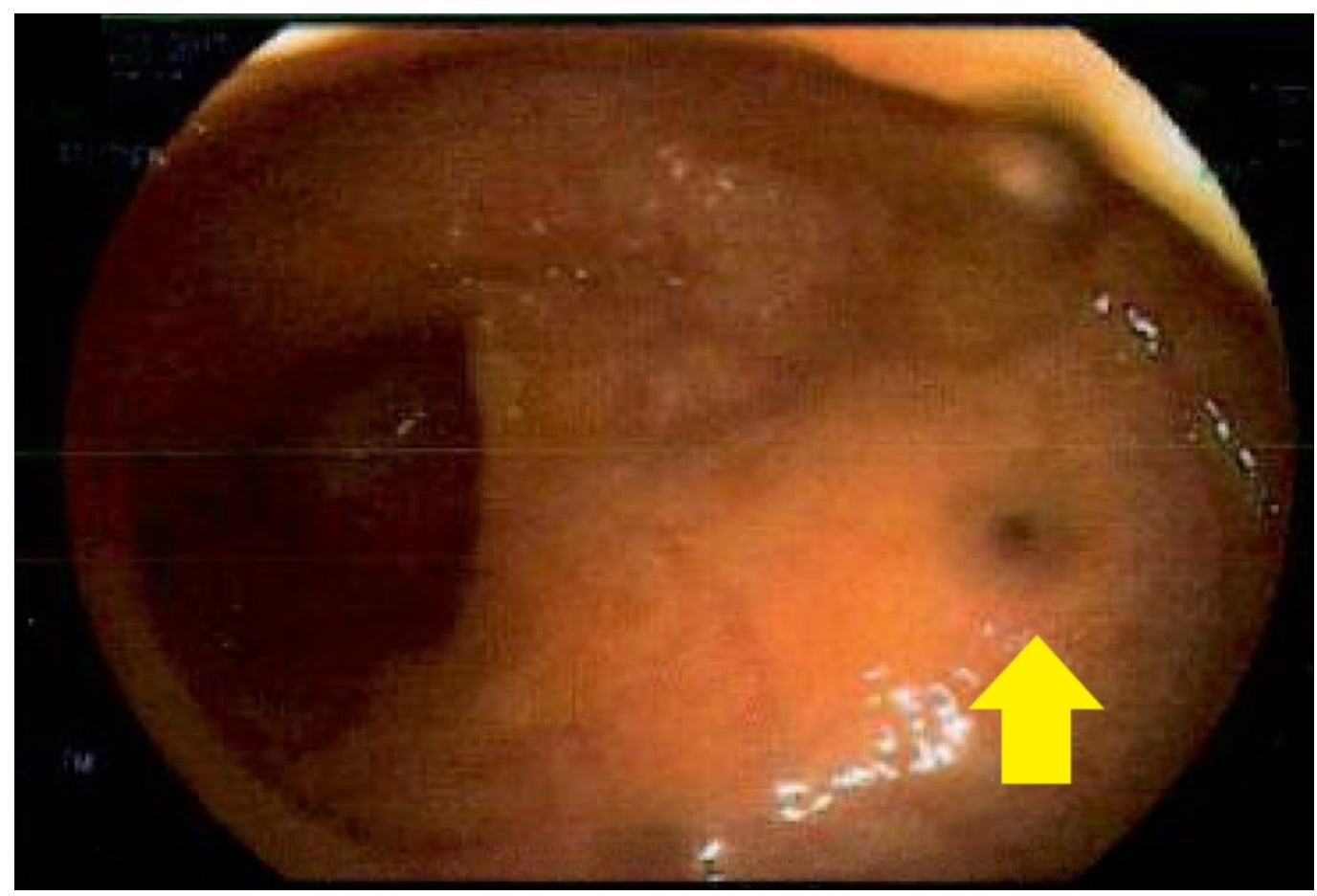

\section{FIGURE 1: Colonoscopy image showing the renocolic fistula opening with surrounding nodularity}

Shortly after, the patient spiked a fever of 102.7F. C-reactive protein (CRP) and erythrocyte sedimentation rate (ESR) were both elevated. Based on the colonoscopy findings and the new fever, a computed tomography (CT) scan of the abdomen and pelvis with contrast was performed and it revealed chronic left kidney pyelonephritis with multiple contiguous abscesses in the inferior left kidney with a staghorn calculus concerning for XGP; it also showed the fistula between the left kidney and the splenic flexure of the colon (Figures 2-3). The patient underwent exploratory laparotomy, takedown and repair of renocolic fistula, partial omentectomy, and left nephrectomy by urology and general surgery teams. The patient had an uncomplicated postoperative course and was discharged home on postoperative day six with 


\section{Cureus}

stable hemoglobin of $8 \mathrm{~g} / \mathrm{dL}$.

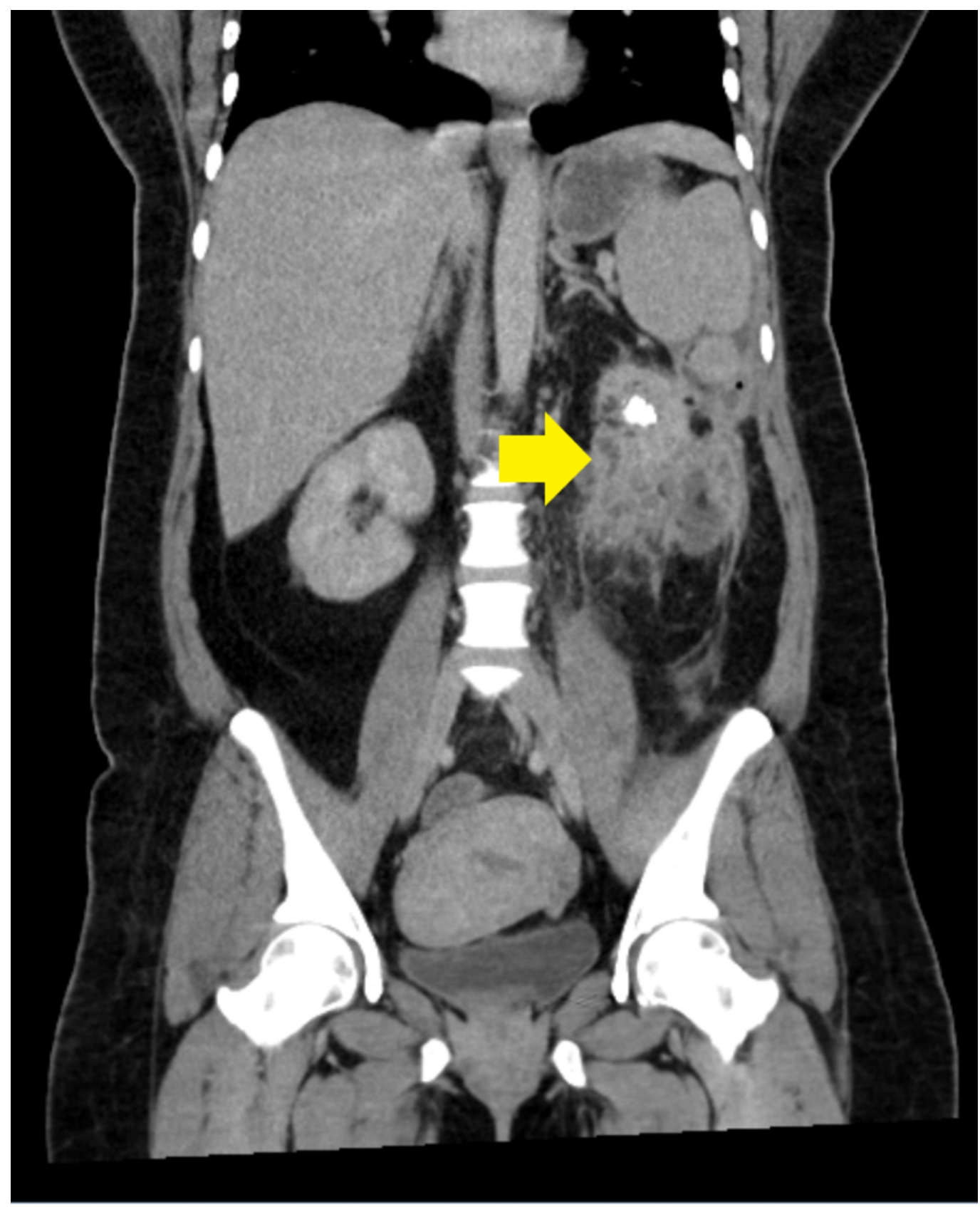

FIGURE 2: Computed tomography scan of the abdomen and pelvis showing xanthogranulomatous pyelonephritis 


\section{Cureus}

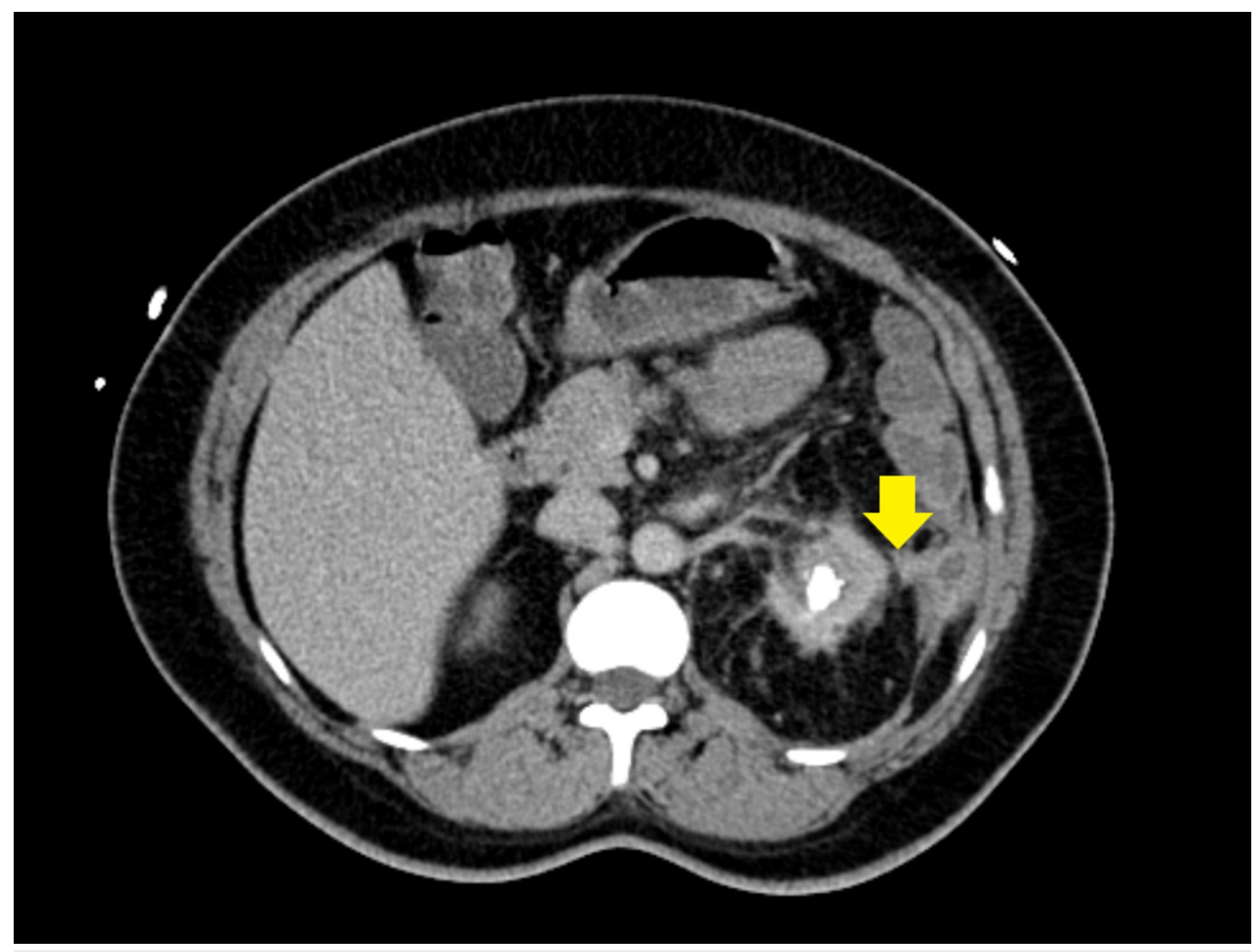

FIGURE 3: Computed tomography scan of the abdomen and pelvis showing the renocolic fistula

\section{Discussion}

XGP is a rare cause of chronic pyelonephritis caused by obstruction of the kidney by infected renal stones [1]. The actual incidence of XGP is estimated to be around $1 \%$ of renal infections cases, although there is no valid statistics to validate this number [1]. The body responds with inflammation in the affected kidney in response to this infection, which is carried out in the form of lipid-laden macrophages and accompanying granulomatous tissue. The foamy histiocytes destroy the kidney and which leads to chronic pyelonephritis [2].

This rare disease is most prevalent in middle-aged women who tend to be at higher risk for recurrent UTIs [4]. The presentation is usually similar to pyelonephritis, including flank pain, fever, and a unilateral renal mass palpated on physical examination [3]. Laboratory testing is typically nonspecific and occasionally reveals anemia and elevation in inflammatory markers [5]. Urinalysis is routinely suggestive of a UTI, and the most common bacterias isolated in urine culture are Escherichia coli, Proteus mirabilis, Pseudomonas species, Enterococcus faecalis, and Klebsiella [5].

In the case we reported, the patient presented with symptomatic anemia and dysuria and had none of the other common signs or symptoms of XGP. In the period of initial management, there was no indication for a CT scan. However, a CT scan and subsequent pathology confirmed the diagnosis of XGP. CT scan usually demonstrates round areas of low density surrounded by a rim of contrast medium [6]. This finding often referred to as the "bear's paw sign" [7]. This classic presentation was seen in our patient.

The lesion is then routinely staged based on the extension of the disease. Stage 1: localized to 
the renal parenchyma; Stage 2: involves the perinephric fat; Stage 3: involves the perinephric fat and/or abdominal wall, and Advanced stage: involves the adjacent gastrointestinal tract [1]. Our patient was easily staged as advanced disease as he had renocolic fistula. In XGP, growing inflammation and increased pressure inside the kidney results in necrosis of the thinning cortex and formation of an abscess. This abscess continues to grow, perforating neighboring structures. In most cases, renocolic fistulas are seen, however, renocutaneous and renobronchial fistulas have also been described before [8].

Staghorn calculi are classically the renal stones infected in XGP and were seen in our patient as well [9]. This first event drives the pathology of XGP and explains the foamy histiocytes seen on histopathology to confirm the diagnosis. The resultant inflammatory response to the infected stones with lipid-laden macrophages results in yellow necrotic tissue seen in infected kidneys [6]. It is proposed that a dysfunction in the macrophages ability to process bacteria results in the destructive inflammation, but the intricacies of the pathology are not well understood [10].

Due to the similarities in clinical presentation and plain film findings, XGP can be initially misdiagnosed as renal carcinoma. However, a history of UTIs and CT findings easily differentiate these diagnoses [11]. In this regard, XGP is a differential that physicians should regard highly in a patient presenting with these typical symptoms. This is additionally important because the prognosis of XGP relies on early diagnosis and management of the disease.

Initial management of XGP usually involves initial antibiotic therapy for the treatment of the acute infection. However, the definitive treatment is surgical with nephrectomy removing all the involved tissues and any extensions of the disease, including fistulas [12]. Although Hippocrates is credited with first describing a renal abscess invading the intestinal tract, the first reported renocolic fistula was in 1841 by Rayer. Since then, the advent of antimicrobial therapy and CT scan have made the pathology rare [13].

This case was presented as a poster at the American College of Gastroenterology annual meeting (Poster: Tahboub L, Abughanimeh O, Numan L, et al. Xanthogranulomatous Pyelonephritis Causing a Renocolic Fistula Presenting as Symptomatic Anemia. American College of Gastroenterology 2018 Annual Scientific Meeting Abstracts. Philadelphia, Pennsylvania; 2018).

\section{Conclusions}

XGP is a rare type of chronic pyelonephritis that is usually a result of chronic obstruction by an infected stone. Spontaneous renocolic fistulas are rare, especially with the advancement in antibiotics and renal stones treatment. XGP can present with mild anemia and dysuria. However, imaging is necessary for diagnosis.

\section{Additional Information Disclosures}

Human subjects: Consent was obtained by all participants in this study. Conflicts of interest: In compliance with the ICMJE uniform disclosure form, all authors declare the following: Payment/services info: All authors have declared that no financial support was received from any organization for the submitted work. Financial relationships: All authors have declared that they have no financial relationships at present or within the previous three years with any organizations that might have an interest in the submitted work. Other relationships: All authors have declared that there are no other relationships or activities that could appear to have influenced the submitted work. 


\section{References}

1. Parsons MA, Harris SC, Longstaff AJ, Grainger RG: Xanthogranulomatous pyelonephritis: a pathological, clinical and aetiological analysis of 87 cases. Diagn Histopathol. 1983, 6:203219.

2. Chuang CK, Lai MK, Chang PL, Huang MS, Chu SH, Wu CJ, Wu HR: Xanthogranulomatous pyelonephritis: experience in 36 cases. J Urol. 1992, 147:333-336. 10.1016/S00225347(17)37229-4

3. Malek RS, Elder JS: Xanthogranulomatous Pyelonephritis: a critical analysis of 26 cases and of the literature. J Urol. 1978, 119:589-593. 10.1016/S0022-5347(17)57559-X

4. Matsuoka Y, Arai G, Ishimaru H, Takagi K, Aida J, Okada Y: Xanthogranulomatous pyelonephritis with a renocolic fistula caused by a parapelvic cyst. Int J Urol. 2006, 13:433435. 10.1111/J.1442-2042.2006.01326.X

5. Goodman M, Curry T, Russel T: Xanthogranulomatous pyelonephritis (XGP): a local disease with systemic manifestations. Report of 23 patients and review of the literature. Medicine. 1979, 58:171-181.

6. Zorzos I, Moutzouris V, Korakianitis G, Katsou G: Analysis of 39 cases of xanthogranulomatous pyelonephritis with emphasis on CT findings. Scand J Urol Nephrol. 2003, 37:342-347. 10.1080/00365590310004752

7. Garrido-Abad P, Rodríguez-Cabello MÁ, Vera-Berón R, Platas-Sancho A: Bear paw sign: xanthogranulomatous pyelonephritis. J Radiol Case Rep. 2018, 12:18-24. 10.3941/Jrcr.V12i11.3415

8. Flood HD, Jones B, Grainger R: Ureterocolic fistula: a unique complication of extracorporeal shock wave lithotripsy. J Urol. 1992, 147:122-124. 10.1016/S0022-5347(17)37154-9

9. Hitti W, Drachenberg C, Cooper M, Schweitzer E, Cangro C, Klassen D, Haririan A: Xanthogranulomatous pyelonephritis in a renal allograft associated with xanthogranulomatous diverticulitis: report of the first case and review of the literature. Nephrol Dial Transplant. 2007, 22:3344-3347. 10.1093/Ndt/Gfm458

10. Parsons MA, Harris SC, Grainger RG, Boss B, Smith JAR, Williams JL: Fistula and sinus formation in xanthogranulomatous pyelonephritis; a clinicopathological review and report of four cases. Br J Urol. 1986, 58:488-493. 10.1111/j.1464-410X.1986.tb05452.x

11. Hortling N, Layer G, Albers P, Schild HH: Xanthogranulomatous pyelonephritis with septic lung metastases and infiltration of the colon. Difficult preoperative differential pulmonary hypernephroma metastasis diagnosis [Article in English, German]. Aktuelle Radiol. 1997, 7:317-320.

12. Peréz LM, Thrasher JB, Anderson EE: Successful management of bilateral xanthogranulomatous pyelonephritis by bilateral partial nephrectomy. J Urol. 1993, 149:100102. 10.1016/S0022-5347(17)36011-1

13. Gibbons RP, Schmidt JD: Reno-colic and reno-colic-cutaneous fistula: report of 3 cases . J Urol. 1965, 94:520-527. 10.1016/S0022-5347(17)63662-0 